\title{
Cost-utility analysis of an implantable cardioverter- defibrillator for the treatment of patients with ischemic or non-ischemic New York Heart Association class II or III heart failure in Colombia
}

\author{
Sara Atehortúa1, Juan Manuel Senior ${ }^{2,3}$, Paula Castro4, Mateo Ceballos ${ }^{5}$, Clara \\ Saldarriaga ${ }^{2}$, Nelson Giraldo ${ }^{2,6}$, Guillermo Mora ${ }^{7,8}$ \\ ${ }^{1}$ Departamento de Economía, Facultad de Ciencias Económicas, Universidad de Antioquia, \\ Medellín, Colombia \\ ${ }^{2}$ Departamento de Cardiología Clínica y Cardiología Intervencionista, Facultad de Medicina, \\ Universidad de Antioquia, Medellín, Colombia \\ ${ }^{3}$ Grupo de Rehabilitación en Salud, Facultad de Medicina, Universidad de Antioquia, Medellín, \\ Colombia \\ ${ }^{4}$ Grupo de Economía de la Salud, Facultad de Ciencias Económicas, Universidad de Antioquia, \\ Medellín, Colombia \\ ${ }^{5}$ Instituto de Evaluación Tecnológica en Salud, Bogotá, D.C., Colombia \\ ${ }^{6}$ Grupo de Epidemiología Clínica, Facultad de Medicina, Universidad de Antioquia, Medellín, \\ Colombia \\ ${ }^{7}$ Departamento de Medicina Interna, Facultad de Medicina, Universidad Nacional de Colombia, \\ Bogotá, D.C., Colombia \\ ${ }^{8}$ Servicio de Electrofisiología, Fundación Santa Fe de Bogotá, Bogotá, D.C., Colombia
}

Introduction: The use of an implantable cardioverter-defibrillator reduces the probability of sudden cardiac death in patients with heart failure.

Objective: To determine the cost-utility relationship of an implantable cardioverter-

Received: 06/12/17

Accepted: $29 / 10 / 18$

Published: $08 / 11 / 18$

Citation:

Atehortúa SC, Senior JM, Castro P, Ceballos M, Saldarriaga C, Mora G, et al. Cost-utility analysis of an implantable cardioverter-defibrillator for the treatment of patients with ischemic or non-ischemic New York Heart Association class II or III heart failure in Colombia. Biomédica. 2019;39:502-12.

https://doi.org/10.7705/biomedica.4235

Corresponding author:

Sara Atehortúa, Departamento de Economía, Facultad de Ciencias Económicas, Universidad de Antioquia, Calle $70 \mathrm{~N}^{\circ}$ 52-21, bloque 13 , oficina 114, Medellín, Colombia

Teléfonos: (574) 2195800 y 2195820

sara.atehortua@udea.edu.co; saritac2005@gmail.com

\section{Author contributions:}

Juan Manuel Senior, Clara Saldarriaga, and Nelson Giraldo: Revision of the clinical evidence and contribution to the design of the decision mode Guillermo Mora and Clara Saldarriaga: Participation in the cost estimation

Sara Atehortúa, Paula Castro, and Mateo Ceballos: Design of the decision model, costs estimation, and results interpretation

Sara Atehortúa, Mateo Ceballos, and Juan Manuel Senior: Writing of the manuscript All authors reviewed and validated the final manuscript.

\section{Funding:}

Departamento Administrativo de Ciencia, Tecnología e Innovación, Colciencias and Ministerio de Salud y Protección Social de Colombia

Conflicts of interest:

Clara Saldarriaga has been consultant for Novartis and Medtronic and speaker for Pfizer and Servier. All other authors declare no competing interests. defibrillator compared to optimal pharmacological therapy for patients with ischemic or nonischemic New York Heart Association class II or III (NYHA II-III) heart failure in Colombia. Materials and methods: We developed a Markov model including costs, effectiveness, and quality of life from the perspective of the Colombian health system. For the baseline case, we adopted a time horizon of 10 years and discount rates of $3 \%$ for costs and $3.5 \%$ for benefits. The transition probabilities were obtained from a systematic review of the literature. The outcome used was the quality-adjusted life years. We calculated the costs by consulting with the manufacturers of the device offered in the Colombian market and using national-level pricing manuals. We conducted probabilistic and deterministic sensitivity analyses.

Results: In the base case, the incremental cost-effectiveness ratio for the implantable cardioverter-defibrillator was USD\$13,187 per quality-adjusted life year gained. For a willingness-to-pay equivalent to three times the gross domestic product per capita as a reference (USD\$19,139 in 2017), the device would be a cost-effective strategy for the Colombian health system. However, the result may change according to the time horizon, the probability of death, and the price of the device.

Conclusions: The use of an implantable cardioverter-defibrillator for preventing sudden cardiac death in patients with heart failure would be a cost-effective strategy for Colombia. The results should be examined considering the uncertainty.

Keywords: Heart failure; defibrillators; implantable; death, sudden, cardiac; cost-benefit analysis; Colombia.

\section{Análisis de costo-utilidad del desfibrilador cardioversor implantable para el tratamiento de pacientes colombianos con insuficiencia cardíaca isquémica o no isquémica de clase II o III según la New York Heart Association}

Introducción. El uso del desfibrilador cardioversor implantable reduce la probabilidad de muerte súbita en pacientes con insuficiencia cardíaca.

Objetivo. Determinar la relación de costo-utilidad de un desfibrilador cardioversor implantable comparado con la terapia farmacológica óptima para pacientes con insuficiencia cardíaca isquémica o no isquémica de clase II o III según la New York Heart Association (NYHA II-III) en Colombia.

Materiales y métodos. Se desarrolló un modelo de Markov que incluyó los costos, la efectividad y la calidad de vida desde la perspectiva del sistema de salud colombiano. Para el caso de base, se adoptó un horizonte temporal de 10 años y una tasa de descuento de $3 \%$ para los costos y de una 3,5\% para los beneficios. Las probabilidades de transición se obtuvieron de una revisión sistemática de la literatura. Los años de vida ajustados 
por calidad se usaron como resultado de salud. Para estimar los costos unitarios se usaron manuales tarifarios nacionales y, para los costos del dispositivo, se consultó a los fabricantes que lo comercializan en el mercado colombiano. Se hicieron análisis de sensibilidad probabilísticos y determinísticos.

Resultados. En el caso base el costo adicional por año de vida ajustado por calidad ganado con el desfibrilador cardioversor implantable fue de USD $\$ 13,187$. Usando un umbral de tres veces el producto interno bruto per cápita como referencia (USD\$19.139 en 2017), el dispositivo sería costo-efectivo para el sistema de salud colombiano. Sin embargo, este resultado depende del horizonte temporal, de la probabilidad de muerte y del precio del dispositivo.

Conclusiones. El uso de un desfibrilador cardioversor implantable sería una estrategia costo-efectiva para Colombia, aunque los resultados deben examinarse teniendo en cuenta la incertidumbre.

Palabras clave: insuficiencia cardíaca; desfibriladores; muerte súbita cardíaca; análisis costo-beneficio; Colombia.

Heart failure is an important medical, social, and economic problem. More than 37.7 million people worldwide suffer from this condition and in 2009 alone, 870,000 new cases per year occurred from 2005 to 2011 were registered in the United States $(1,2)$. Heart failure is associated with a high financial burden, consuming approximately $2 \%$ of the total health costs in developed countries (3). The costs of care for this condition totaled 30.7 billion dollars for the United States health system in 2012 (4).

Despite the scarce epidemiological data in the majority of developing countries, it is estimated that the prevalence of heart failure among the adult population ranges from 2 to $3 \%$ and tends to increase with age (5). In Colombia, there are no accurate disease prevalence registries, but it is known that $40 \%$ of hospitalizations due to cardiovascular diseases are associated with heart failure (6).

Although optimal pharmacological therapy (OPT) is highly recommended for the management of patients with heart failure, it is not always an effective alternative for the prevention of sudden cardiac death (7), one of the principal causes of death in patients with this condition. For this reason, the implantable cardioverter-defibrillator (ICD) was developed; it is a device that has been shown to reduce the likelihoods of death from all causes and of sudden cardiac death in patients with ischemic and non-ischemic heart failure and left ventricular systolic dysfunction (LVSD) $(8,9)$.

The implantation of an ICD is increasingly common in Colombia, and its high cost could imply an important increase in the financial burden for the health system. The objective of this study was to determine the costeffectiveness relationship between the use of an ICD and OPT compared to the OPT alone to avoid sudden cardiac death in patients with heart failure from the perspective of the Colombian health system.

\section{Materials and methods}

This cost-utility analysis was conducted from the perspective of the Colombian health system including the direct care costs financed by the health system. The study population was composed by persons with NYHA II-III functional heart failure, an ejection fraction $<35 \%$, LVSD, without a previous history of sudden cardiac death, and with ischemic or non-ischemic cardiomyopathy. The analysis was conducted in this group of people because they are at greater risk of sudden cardiac death and would, therefore, benefit most from an ICD implantation $(8,9)$. The initial age of our hypothetical cohort was 60 years. For the base case, a time horizon of 10 years and discount 
rates of $3 \%$ for costs and $3.5 \%$ for benefits were assumed according to the recommendations of the methodological guide for developing economic evaluations within Colombia's clinical practice guidelines (10).

To estimate the expected costs and benefits from each alternative, a decision tree that simulated outcomes associated with the ICD surgical implantation phase and a Markov model with annual cycles were employed to simulate short and long-term effects (figure 1). Patients who underwent an ICD implantation could either experience post-operatory death (death occurring during the first 30 days after the surgical procedure) or they could survive. They could also enter into one of the stages that make up the Markov model: Suffering sudden cardiac death, non-sudden cardiac death, or death due to non-cardiac causes; they could experience no event, or they could experience some ICD-related complication. Fractures, displacement, $w$ and severe infection were the ICD related complications considered because they usually are more frequent and imply significant cost increases. For severe infections, the possibility of the patient dying from such cause was considered. For the OPT alternative, the same outcomes were considered, but post-operatory ICD-related death and complications were excluded.

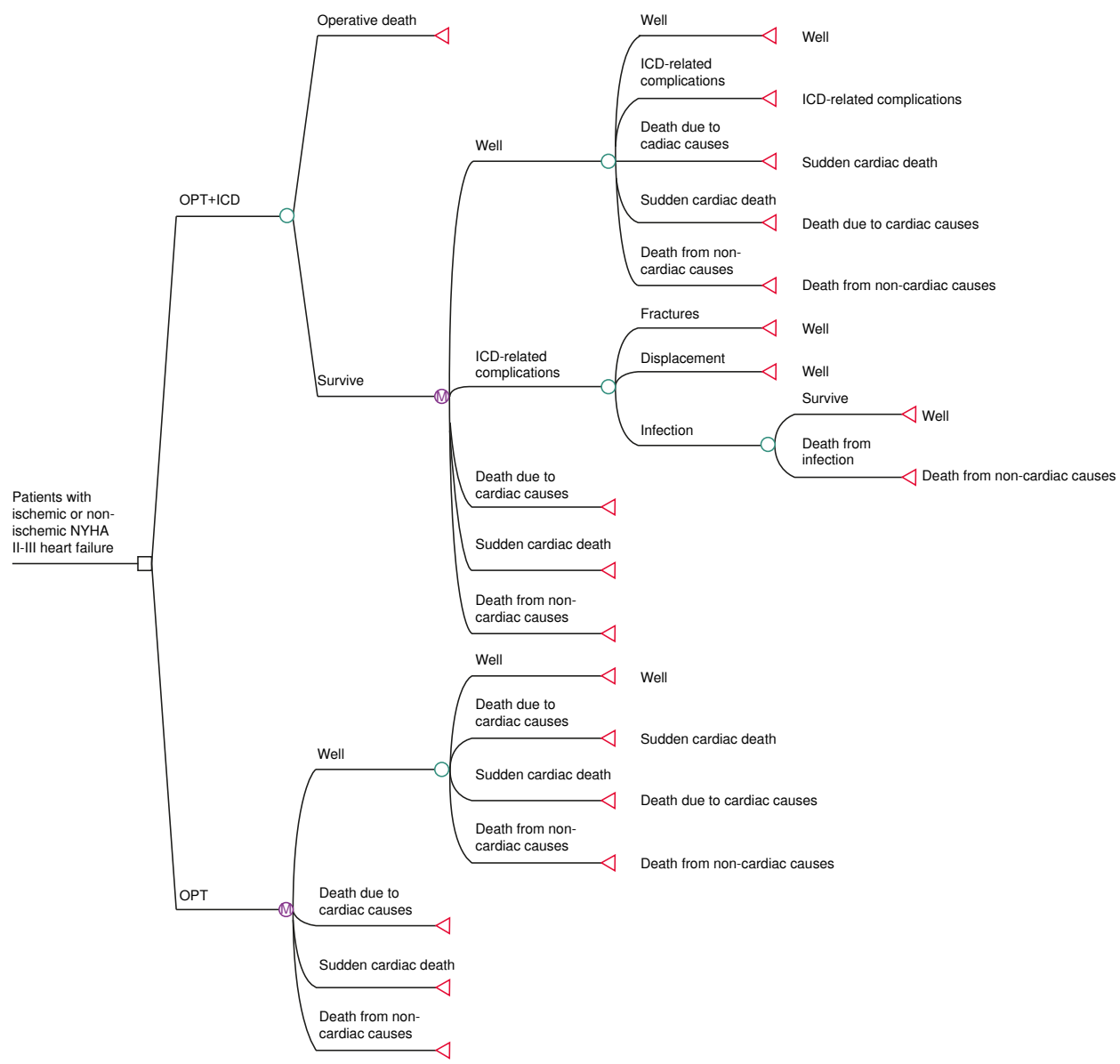

OPT: Optimal pharmaceutical therapy; ICD: Implantable cardioverter defibrillator; NYHA II-III: New York Heart Association Classes II-III

Figure 1. Decision model 
The effectiveness outcome employed was the quality-adjusted life years (QALY). This outcome focuses on patients and combines the years of life gained and the health-related quality of life score for patients with heart failure.

Transition probabilities were extracted from clinical studies found in a systematic review of the literature in Medline, EMBASE, and Cochrane Library databases included in a Colombian clinical practice guideline for heart failure (CPG-HF) (11). The search terms used were heart failure, cardiac failure, myocardial failure, heart decompensation, NYHA, defibrillators, implantable, and cardioverter-defibrillator.

From the available evidence, we used a meta-analysis aggregating evidence from various clinical trials (8) conducted in ischemic and nonischemic patients, which focused only on ICD (without including the effects of cardiac resynchronization therapy) and excluded heterogeneous trial results. To calculate the probability of all causes of death and sudden cardiac death in the ICD branch of the tree, we multiplied the probability of death in the OPT branch (baseline) by the relative risk $(\mathrm{RR})$ reported in the meta-analysis $(0.73$ and 0.4 , respectively). Using this procedure, we obtained the probabilities reported in table 1 . The probability of operative death used in the base case was also obtained from this meta-analysis (8).

The probability of non-sudden cardiac death was obtained by subtracting all-cause mortality from the sudden cardiac death and death from other noncardiac causes. Age-adjusted probability of cardiac death due to all causes was taken from the statistics of the Colombian Departamento Administrativo Nacional de Estadísticas (DANE). For the life tables by age groups, we considered mortality due to heart failure (CIE-10 303 and 306 codes) and mortality from other causes (those reported).

Table 1. Model parameters, base case estimates, and data sources

\begin{tabular}{|c|c|c|c|c|}
\hline Alternative & Variable & $\begin{array}{l}\text { Base case } \\
\text { estimates }\end{array}$ & $\begin{array}{l}\text { Distribution parameters } \\
\text { (alpha, beta, min-max) }\end{array}$ & $\begin{array}{l}\text { Data } \\
\text { source }\end{array}$ \\
\hline \multicolumn{5}{|l|}{ Probabilities } \\
\hline \multirow[t]{7}{*}{ ICD } & Operative death & 0 & $a=0 ; \beta=2,774$ & (8) \\
\hline & All-cause mortality & 0.178 & $a=385 ; \beta=1,790$ & (8) \\
\hline & Sudden cardiac death & 0.037 & $a=110 ; \beta=2,825$ & (8) \\
\hline & ICD-related complications & 0.062 & $a=169 ; \beta=2,554$ & (8) \\
\hline & Devise movement & 0.5 & $a=16 ; \beta=16$ & (8) \\
\hline & Infection & 0.2 & $a=10 ; \beta=40$ & (8) \\
\hline & Death from infection & 0.21 & $a=1.93 ; \beta=7.27$ & $(12,13)$ \\
\hline \multirow{2}{*}{ OPT } & All-cause mortality & 0.284 & $a=604 ; \beta=1,522$ & (8) \\
\hline & Sudden cardiac death & 0.108 & $a=317 ; \beta=2,605$ & (8) \\
\hline \multicolumn{5}{|l|}{ Utility weight } \\
\hline & Well (equal to both alternatives) & 0.845 & $a=6.164 ; \beta=1.131$ & (14) \\
\hline & ICD-related complications & 0.75 & $\mathrm{~N} / \mathrm{A}$ & $(15,16)$ \\
\hline \multicolumn{5}{|c|}{$\begin{array}{l}\text { Medical and procedure } \\
\text { related costs }\end{array}$} \\
\hline OPT & $\begin{array}{l}\text { Medications, consultations, and } \\
\text { laboratory tests }\end{array}$ & 313.04 & $282.08-343.95$ & \\
\hline \multirow[t]{5}{*}{ ICD } & Device price & $7,259.46$ & $6,539.44-7,793.12$ & \\
\hline & Implant procedure & 300.28 & $289.80-337.59$ & \\
\hline & Post-implant hospitalization & 73.39 & $70.11-84.01$ & \\
\hline & Major infection & 194.17 & $184.57-223.73$ & \\
\hline & Fracture/Displacement & 187.83 & $180.60-213.83$ & \\
\hline
\end{tabular}

OPT: Optimal pharmaceutical therapy; ICD: Implantable cardioverter defibrillator; N/A: Not applicable 
Given that the probability of death due to infection was not reported in any of the clinical trials available, we used the information reported in economic evaluations of ICD use in patients with heart failure (12). The model assumed that the benefits of the ICD found in the follow-up of the clinical trials were constant and could be extrapolated to all time frames proposed. However, considering age-adjusted probabilities, we considered an increase in the mortality rate over time for a more realistic scenario.

For all transition probabilities of the model, beta distributions with a and $\beta$ parameters were constructed based on population data. For the probability of death by infection, $a$ and $\beta$ parameters were constructed from the mean and standard deviation of the estimates.

To determine utility weights for the model states, we reviewed the Tufts University's Cost-Effectiveness Analysis (CEA) Registry to obtain those used in heart failure clinical trials, as well as multiple estimates from cohort studies. For the base case, we chose data calculated in the Multicenter Automatic Defibrillator Implantation Trial-Cardiac Resynchronization Therapy (MADITCRT) clinical trial for the "well" state (13) due to its proximity to the population, the alternatives analyzed, and the detail of the data presented while for the ICD "complications" state, the calculation was taken from the literature $(14,15)$. It was assumed that ICD implantation did not change the quality of life of the patients who remained in the well state of the Markov model. The weights used in the base case are shown in table 1.

The direct medical costs associated with each alternative and branch of the model were calculated based on the identification and measurement of the resources consumed. This calculation was performed through the construction of a type-case according to the review of the CPG-HF clinical recommendations and from health care protocols of a Colombian hospital. This type-case was validated and modified based on an informal consensus of general internists and cardiologists who are experts in the field (11). Details regarding the units of measurement and the frequency of resources included can be found in the CPG-HF (11).

To calculate the cost of the procedures, we used the Colombian Instituto de Seguros Sociales tariffs from 2001 with a 30\% adjustment for the base case and $25 \%$ and $48 \%$ adjustments for the minimum and maximum values, respectively. According to the methodological guide for developing economic evaluations in Colombia, these adjustments update the costs of the procedures to the current conditions of the Colombian market (10).

The unit prices of medications were calculated with the information reported in the institution-laboratory channel of the Colombian pricing and medication information system for 2017. The minimum, mean, and maximum prices of each presentation correspond to the weighted estimates of the different medication presentations, which include both generic and brand name drugs.

The price of the ICD was obtained from the quotations of two companies that manufacture and market this type of device in the country. In the base case, we considered the average prices of the two types of devices (singleand dual-chamber). Supposedly, the device needs a replacement every 5 years and the costs associated with this procedure correspond exclusively to the implant of the device battery and does not include the cost of the electrodes and wires. The average ICD price was calculated in USD $\$ 7,259.46$ with a minimum price of USD $\$ 6,539.44$ and a maximum of USD\$ 7,793.12. 
To determine the costs associated with the OPT, we included the standard medical management with three types of basic medications: Angiotensinconverting enzyme inhibitors (ACEI) or angiotensin II receptor antagonists (ARA II), beta-receptor blockers, and diuretics as reviewed by specialists, as well as some laboratory exams and diagnostic aids. The cost of the OPT used in the base case is shown in table 1.

For the ICD-associated costs, we also considered OPT management, the price of the device (including the cardioverter-defibrillator, the electrodes, and the wires), and the costs of the implantation surgery and the subsequent recovery hospitalization. Details regarding the specific resources included in each component can be found in the CPG-HF (11). The prices of all of the elements making up the total cost of the ICD considered in the base case are shown in table 1.

In addition to the costs of the comparison alternatives, we considered the resources consumed in the treatment of ICD complications. In the initial emergency procedures, we included care for severe infection, antibiotic treatment, consultation with specialists, and the price of the electrode removal surgery price and replacement with a new device (which included the implantation procedure and subsequent hospitalization). Electrode displacement or fracture included emergency care, consultations, and repositioning procedures. The additional cost associated with each complication for the base case is shown in table 1 considering that in the case of severe infection, the cost of a new ICD device should be added.

To address uncertainty, we conducted deterministic sensitivity analyses of the cost of the device and the ICD replacement time, as well as of the probability of death due to all causes over time. Additionally, we did a tornado analysis to assess the impact of all the variables in the results. Finally, we performed a subgroup analysis for ischemic and non-ischemic patients using the different data provided by Theuns, et al. (8).

We also performed a probabilistic sensitivity analysis with 10,000 Monte Carlo simulations using beta distributions for transition probabilities and utility weights and uniform distributions for costs. The distribution parameters for the inputs of the model are presented in table 1.

To determine the relationship between costs and QALY, we used the incremental cost-effectiveness ratio (ICER), which was compared with a cost-effectiveness threshold. Although the explicit definition of the threshold is a controversial topic, this study followed the recommendation of the World Health Organization of a threshold between 1 and 3 times the country's per capita gross domestic product (GDP) (16). According to the official data from Colombia's central bank, the threshold for 2017 ranged between USD \$ 6,308 and USD $\$ 19,139$. The model and the statistical analyses were done using TreeAge Pro 2013 (TreeAge Software Inc., Williamstown, MA). Costs in US dollars (USD) were calculated using the representative exchange rate for the Colombian market in 2017 reported by the country's central bank in COP\$ 2,951.32 per dollar.

\section{Results}

In the base case and over a time horizon of 10 years, the cost for the ICD per QALY gained was USD\$13,187. This result led to the conclusion that the device would be a cost-effective alternative for the Colombian health system, 
as it did not exceed USD $\$ 19,139$, i.e., the equivalent of three times the Colombian per capita GDP for 2017. However, when we considered a time horizon of 5 years, the ICER reached USD $\$ 20,569$, which is higher than the threshold used (table 2).

Table 2. Cost-effectiveness of OPT compared to OPT plus ICD

\begin{tabular}{|c|c|c|c|c|c|}
\hline Strategy & $\begin{array}{l}\text { Costs } \\
\text { (USD) }\end{array}$ & $\begin{array}{c}\text { Incremental } \\
\text { cost }\end{array}$ & QALY & $\begin{array}{c}\text { Incremental } \\
\text { QALY }\end{array}$ & ICER \\
\hline \multicolumn{6}{|l|}{ Base-case } \\
\hline OPT & 974 & & 2.6056 & & \\
\hline $\begin{array}{c}\text { OPT + ICD } \\
\text { Sensitivity ana } \\
\text { time horizon }\end{array}$ & 10,992 & 10,018 & 3.3653 & 0.7596 & 13,187 \\
\hline OPT & 890 & & 2.3859 & & \\
\hline OPT + ICD & 10,322 & 9,432 & 2.8445 & 0.4585 & 20,569 \\
\hline OPT & 987 & & 2.6385 & & \\
\hline OPT + ICD & 11,194 & 10,207 & 3.5225 & 0.8840 & 11,546 \\
\hline \multicolumn{6}{|c|}{$\begin{array}{l}\text { Analysis by subgroups } \\
\text { (ischemic and non-ischemic) }\end{array}$} \\
\hline OPT & 973 & & 2.6029 & & \\
\hline OPT + ICD & 11,314 & 10,341 & 3.5449 & 0.9420 & 10,977 \\
\hline OPT & 1,243 & & 3.3146 & & \\
\hline OPT + ICD & 12,252 & 11,008 & 4.0488 & 0.7342 & 14,992 \\
\hline
\end{tabular}

OPT: Optimal pharmaceutical therapy; ICD: Implantable cardioverter defibrillator; ICER: Incremental costeffectiveness ratio; QALY: Quality-adjusted life years

Probability of death from all causes with ICD Probability of death from all causes with OPT

Effectiveness discount Utility weight for the state Well ICD price Cost discount Probability of infection Utility weight for the ICD-related complications Probability of death from infection Probability of ICD-related complications

OPT cost Probability of operative death Implant procedure cost Post-implant hospitalization cost Fracture cost Infection cost Displacement cost Probability of sudden cardiac death with OPT Probability of sudden cardiac death with ICD

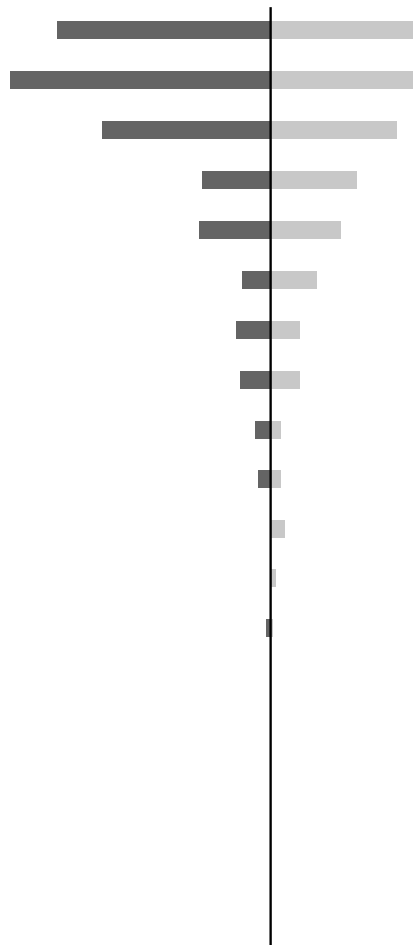

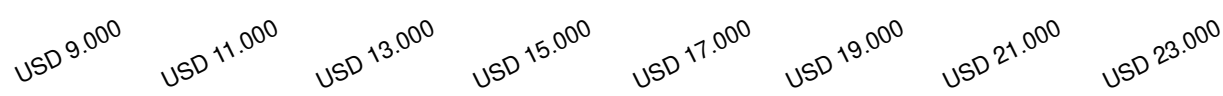

Incremental cost-effectiveness relationship (ICER)

OPT: Optimal pharmaceutical therapy; ICD: Implantable cardioverter defibrillator

Figure 2. Tornado diagram of the one-way sensitivity analysis 


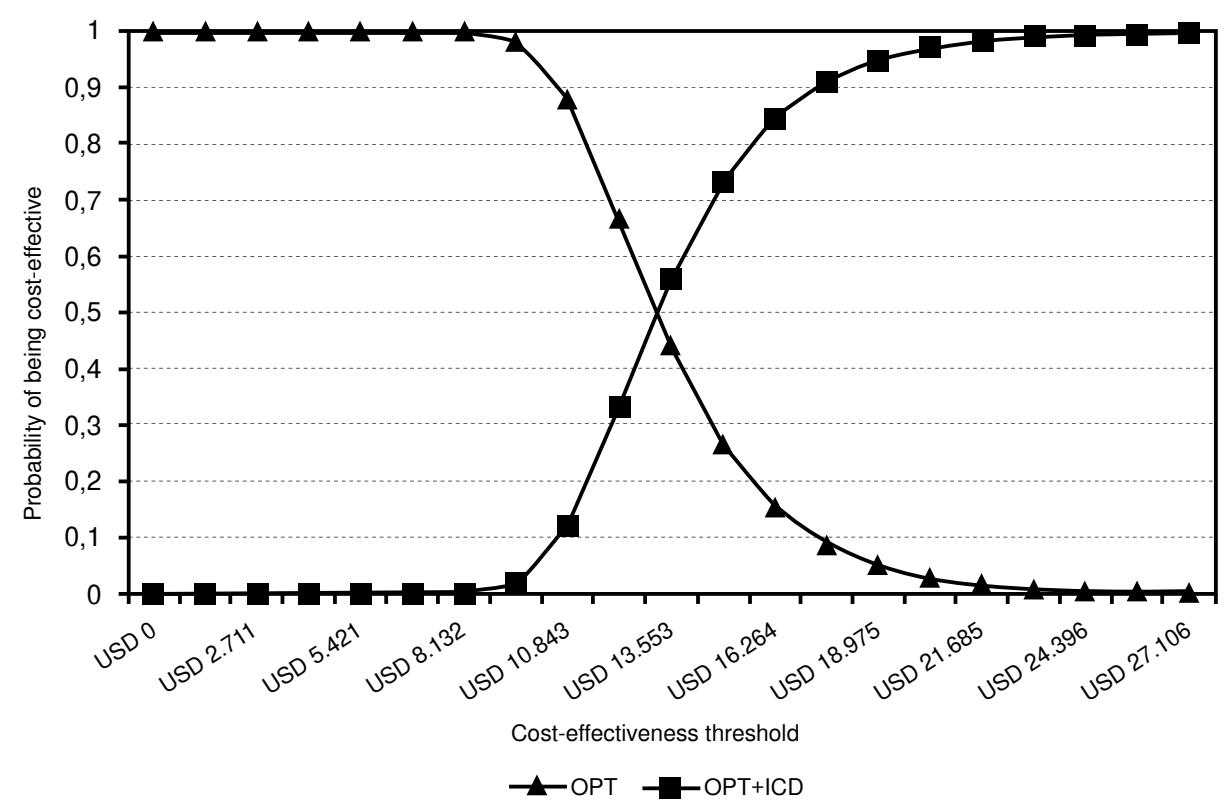

OPT: Optimal pharmaceutical therapy; ICD: Implantable cardioverter defibrillator

Figure 3. Cost-effectiveness acceptability curve

When considering a device-replacement time of 7 years, the ICER considerably decreased to USD $\$ 11,865$. Furthermore, assuming that all variables kept constant over time but modifying the ICD price, we still found it to be a cost-effective alternative provided that its cost did not exceed USD $\$ 10,685$.

When the cost-effectiveness relationship of the ICD was analyzed for ischemic patients, we calculated a cost of USD \$ 10,977 per QALY gained while for non-ischemic patients this value increased to USD\$14,992. Considering a threshold of USD $\$ 19,139$, we concluded that the ICD was a cost-effective alternative for both types of patients, although a better relationship between costs and QALY was found for ischemic patients (table 2).

The tornado analysis allowed us to conclude that the probability of death variables was more relevant than others to change the result obtained in the base case (figure 2). Finally, in the probabilistic sensitivity analysis, if the willingness to pay per QALY equaled USD\$19,139, the probability that the ICD would be cost-effective was $95.1 \%$ (figure 3 ).

\section{Discussion}

The results of this economic analysis suggest that the ICD would be a cost-effective alternative for the Colombian health system in the treatment of patients with both ischemic and non-ischemic heart failure, an ejection fraction $<35 \%$, LVSD, and functional class NYHA II-III over a time horizon of 10 years. This was consistent as long as its price did not exceed USD\$10,685. The decision also depended largely on the threshold decided upon, as the base case results were sensitive to this choice.

These results are similar to other economic evaluations published in developed countries, which have found that although the ICD implies an increase in cost for the health system, it is cost-effective at a patientpopulation level as its use significantly reduces mortality $(14,15,17,18)$. However, the majority of the economic evaluations published have been 
designed in the context of developed countries and, as such, they respond to different characteristics from those in Colombia, which make them not completely comparable.

To the best of our knowledge, only two evaluations in the Latin American context have been published $(12,19)$. The first found that the ICD was not cost-effective for the Brazilian health system but it had a better costeffectiveness relationship for patients at greater risk of sudden cardiac death. The second showed heterogeneous results depending on the cohort of patients and the specific Argentinian health sub-system.

The main difference between our results and those from these two papers relies on the effectiveness source used. While the Brazilian study used data from a local cohort of patients and a meta-analysis, our research resorted to data from a recent international aggregate study, which directly impacts the cost-effectiveness estimation. Similarly, the Argentinian study considered three randomized clinical trials independently and not aggregated.

Recently, the Danish Study to Assess the Efficacy of ICD in Patients with Non-Ischemic Systolic Heart Failure on Mortality (DANISH) reported the lack of any survival benefit of ICD in patients with non-ischemic cardiomyopathy, which could alter the results of cost-utility analyses $(20,21)$. However, the study did not address the mortality effects in non-ischemic cardiomyopathy patients who only had ICD. On the other hand, a new meta-analysis including the DANISH trial found a decrease in mortality in this population $(22,23)$.

Some of the limitations of this study are related to the probabilities of death, which are the more sensitive variables for cost-effectiveness conclusions. Estimating probabilities for the Colombian population could be difficult because we would need information from a randomized clinical trial currently not available. This forced us to use probabilities obtained from the best clinical evidence available. A broad methodological discussion about clinical evidence can be found in the CPG-HF recommendations (11).

Another limitation is the lack of weighted utility estimates for Colombia. The results could vary if the health estimates to be included in the Markov model were different for the Colombian population. Estimating valid utility values for the local setting is a research effort that could make the cost utility analysis more robust in the present study and in future ones conducted in the country, as the QALY constructed would correspond to the Colombian population.

Concerning costs, one limitation that should be mentioned stems from the fact that the ICD pricing data were obtained via direct quotation from two of the four companies that manufacture and distribute the device in the Colombian market, as there are no institutional registries for determining whether only these companies effectively sell the devices. More importantly, no systematic information on the prices that care providers and insurers pay were available to establish whether differences in contracts or operating margins could modify the prices actually paid compared to those in the market.

Assuming that five-year replacement costs exclude those costs of the electrodes and other accessories could be a limitation, as they could require replacement in some cases either because they no longer work adequately or due to complications in the procedure. Unfortunately, there are no data in 
Colombia to establish the replacement percentage required for electrodes and other accessories. We hope such a percentage would be minimum, given that the elective change rate varies between $1 \%$ and $5 \%$ depending on the type of electrode used (24).

Another possible limitation lies on the OPT costs, as we used the weighted average per molecule for an important group of medications in the base case. For renin-angiotensin-aldosterone system-blocking medications, for example, we used the weighted average, which includes both ARA Ils and ACE inhibitors, although these are indicated only for patients who do not tolerate the other medication. There is currently no information to establish the proportion of patients who use one or the other group of medications to build a base case more in line with the Colombian reality. Additionally, it is not possible to know whether all patients who use an ARA II do so because of intolerance to ACE inhibitors or if the medication was prescribed from the beginning of their pharmacological treatment. Thus, we deemed that the best way to present this cost was to consider both groups of medications.

Cardiovascular disease is one of the top five causes of death in the world and it represents an important burden for the health systems. Our study provides comparative evidence about costs and effectiveness very useful for Colombian and Latin American health authorities at micro and macro levels.

\section{Acknowledgements}

The authors thank the developer team of the Colombian clinical practice guidelines for the prevention, diagnosis, and treatment of heart failure for their comments and contributions to the study.

\section{References}

1. McMurray JJ, Petrie MC, Murdoch DR, Davie AP. Clinical epidemiology of heart failure: Public and private health burden. Eur Heart J. 1998;19:9-16.

2. Ziaeian B, Fonarow GC. Epidemiology and aetiology of heart failure. Nat Rev Cardiol. 2016;13:368-78. https://doi.org/10.1038/nrcardio.2016.25

3. Berry C, Murdoch DR, McMurray JJ. Economics of chronic heart failure. Eur J Heart Fail. 2001;3:283-291. https://doi.org/10.1016/S1388-9842(01)00123-4

4. Mozaffarian D, Benjamin EJ, Go AS, Arnett DK, Blaha MJ, Cushman M, et al. Heart disease and stroke statistics: 2015 update: A report from the American Heart Association Statistics Committee and Stroke Statistics. Circulation. 2015;131:29-322. https://doi.org/10.1161/CIR.0000000000000152

5. Bui AL, Horwich TB, Fonarow GC. Epidemiology and risk profile of heart failure. Nat Rev Cardiol. 2011;8:30-41. https://doi.org/10.1038/nrcardio.2010.165

6. Tamayo D, Rodríguez V, Rojas M, Rincón M, Franco C, Ibarra M, et al. Costos ambulatorios y hospitalarios de la falla cardiaca en dos hospitales de Bogotá. Acta Médica Colombiana. 2013;38:208-12.

7. Haas G, Abraham W. Comprehensive pharmacologic management strategies for heart failure. In: Yu C, Hayes D, Auricchio A, editors. Cardiac resynchronization therapy. Massachusetts: Blackwell; 2008. p. 15-34.

8. Theuns DA, Smith T, Hunink MG, Bardy GH, Jordaens L. Effectiveness of prophylactic implantation of cardioverter-defibrillators without cardiac resynchronization therapy in patients with ischaemic or non-ischaemic heart disease: A systematic review and metaanalysis. Europace. 2010;12:1564-1570. https://doi.org/10.1093/europace/euq329

9. Ezekowitz JA, Rowe BH, Dryden DM, Hooton N, Vandermeer B, Spooner C, et al. Systematic review: Implantable cardioverter defibrillators for adults with left ventricular systolic dysfunction. Ann Intern Med. 2007;147:251-262.

https://doi.org/10.7326/0003-4819-147-4-200708210-00007 
10. Ministerio de la Protección Social, Colciencias, Centro de Estudios e Investigación en Salud de la Fundación Santa Fe de Bogotá, Escuela de Salud Pública de la Universidad de Harvard. Guía metodológica para el desarrollo de Guías de atención integral en el Sistema General de Seguridad Social en Salud Colombiano. Accessed on: October 1, 2018. Available at: https://www.minsalud.gov.co/salud/Documents/Gu\%C3\%ADa\%20 Metodol\%C3\%B3gica\%20para\%20la\%20elaboraci\%C3\%B3n\%20de\%20gu\%C3\%ADas.pdf

11. Ministerio de Salud y Protección Social, Colciencias, Universidad de Antioquia. Guía de práctica clínica para la prevención secundaria, diagnóstico, tratamiento y rehabilitación de la falla cardíaca en población mayor de 18 años clasificación B, C y D: Guía completa. Sistema General de Seguridad Social en Salud. Accessed on: October 1, 2018. Available at: http://gpc.minsalud.gov.co/gpc sites/Repositorio/Conv_637/GPC_falla_cardiaca/GPC\%20 Falla\%20Cardiaca\%20Profesionales\%20No\%2053.pdf

12. Ribeiro RA, Stella SF, Camey SA, Zimerman LI, Pimentel M, Rohde LE, et al. Costeffectiveness of implantable cardioverter-defibrillators in Brazil: Primary prevention analysis in the public sector. Value Health. 2010;13:160-168. https://doi.org/10.1111/j.1524-4733.2009.00608.x

13. Noyes K, Veazie P, Hall WJ, Zhao H, Buttaccio A, Thevenet-Morrison K, et al. Costeffectiveness of cardiac resynchronization therapy in the MADIT-CRT trial. J Cardiovasc Electrophysiol. 2013;24:66-74. https://doi.org/10.1111/j.1540-8167.2012.02413.x

14. Sanders GD, Kong MH, Al-Khatib SM, Peterson ED. Cost-effectiveness of implantable cardioverter defibrillators in patients $\geq 65$ years of age. Am Heart J. 2010;160:122-31. https://doi.org/10.1016/j.ahj.2010.04.021

15. Cowie MR, Marshall D, Drummond M, Ferko N, Maschio M, Ekman M, et al. Lifetime cost-effectiveness of prophylactic implantation of a cardioverter defibrillator in patients with reduced left ventricular systolic function: Results of Markov modelling in a European population. Europace. 2009;11:716-26. https://doi.org/10.1093/europace/eup068

16. World Health Organization. Macroeconomics and Health: Investing in health for economic development. Report for the Commission on macroeconomics and health. Accessed on: October 1, 2018. Available at: http://apps.who.int/iris/bitstream/10665/42435/1/924154550X.pdf

17. Smith T, Jordaens L, Theuns DA, van Dessel PF, Wilde AA, Hunink MG. The costeffectiveness of primary prophylactic implantable defibrillator therapy in patients with ischaemic or non-ischaemic heart disease: A European analysis. Eur Heart J. 2013;34:211 219. https://doi.org/10.1093/eurheartj/ehs090

18. Gandjour A, Holler A, Dipl-Ges-Ök, Adarkwah CC. Cost-effectiveness of implantable defibrillators after myocardial infarction based on 8-year follow-up data (MADIT II). Value Health. 2011;14:812-7. https://doi.org/10.1016/j.jval.2011.02.1180

19. Alcaraz A, González-Zuelgaray J, Augustovski F. Costo-efectividad del cardiodesfibrilador implantable en pacientes con factores de riesgo de muerte súbita en Argentina. Value Health. 2011;14:33-38. https://doi.org/10.1016/j.jval.2011.05.030

20. Epstein LM, Love CJ, Wilkoff BL, Chung MK, Hackler JW, Bongiorni MG, et al. Superior vena cava defibrillator coils make transvenous lead extraction more challenging and riskier. J Am Coll Cardiol. 2013;61:987-989. https://doi.org/10.1016/j.jacc.2012.12.014

21. Køber L, Thune JJ, Nielsen JC, Haarbo J, Videbæk L, Korup E, et al. Defibrillator implantation in patients with nonischemic systolic heart failure. N Engl J Med. 2016;375:1221-1230. https://doi.org/10.1056/NEJMoa1608029

22. Narayanan A, Reddy V, Deshmukh B, Adabag B. Efficacy of implantable cardioverterdefibrillator therapy in patients with nonischemic cardiomyopathy: A systematic review and meta-analysis of randomized controlled trials. JACC Clin Electrophysiol. 2017;3:962-70. https://doi.org/10.1016/j.jacep.2017.02.006

23. Siddiqui WJ, Aggarwal S, Rafique M, Singh S, Kutalek S, Eisen HJ. Prophylactic use of the implantable cardioverter-defibrillator and its effect on the long-term survival, cardiovascular and sudden cardiac death in nonischemic cardiomyopathy patients-a systematic review and meta-analysis. Heart Fail Rev. 2018;23:181-90. https://doi.org/10.1007/s10741-018-9671-6

24. Epstein LM, Love CJ, Wilkoff BL, Chung MK, Hackler JW, Bongiorni MG, et al. Superior vena cava defibrillator coils make transvenous lead extraction more challenging and riskier. J Am Coll Cardiol. 2013;61:987-9. https://doi.org/10.1016/j.jacc.2012.12.014 